\title{
Shepherding community engagement to strengthen the local food system in Northeast Iowa
}

Arlene E. Enderton, ${ }^{*}$ * Corry M. Bregendahl, ${ }^{\mathrm{b}}$ and Alice S. Topaloff ${ }^{\mathrm{c}}$

Iowa State University Extension and Outreach

Submitted June 21, 2016 / Revised November 10, 2016, and January 24, 2017 /

Accepted January 25, 2017 / Published online March 7, 2017

Citation: Enderton, A. E., Bregendahl, C. M., \& Topaloff, A. S. (2017). Shepherding community

engagement to strengthen the local food system in Northeast Iowa. Journal of Agriculture, Food Systems,

and Community Development, 7(2), 85-100. http://dx.doi.org/10.5304/jafscd.2017.072.011

Copyright (C) 2017 by New Leaf Associates, Inc.

\section{Abstract}

In this case study, we describe how a multistakeholder collaboration in Northeast Iowa is using a type of systems leadership that we call "shepherding" in order to engage a six-county regional community in creating food systems change. Shepherding is an intentional process of fostering trust, connecting food systems actors, tracking

a * Corresponding author: Arlene E. Enderton, Iowa State University Extension and Outreach Local Foods Program; 209 Curtiss Hall; 519 Farmhouse Lane; Ames, Iowa 50011 USA; arlene@,iastate.edu

b Corry Bregendahl, Iowa State University Extension and Outreach Local Foods Program; 209 Curtiss Hall; 519

Farmhouse Lane; Ames, Iowa 50011 USA; corry@iastate.edu

c Alice Topaloff, Iowa State University Extension and Outreach Local Foods Program; 209 Curtiss Hall; 519

Farmhouse Lane; Ames, Iowa 50011 USA; topaloff@iastate.edu

\section{Disclosure}

Funding for this article was provided by the W. K. Kellogg Foundation. readiness, and making strategic requests to help interested community members define active food system roles for themselves. In Northeast Iowa, "shepherds" usually have been paid staff of the Northeast Iowa Food and Fitness Initiative partner organizations. Some literature characterizes leadership by paid staff as an asset, but such leadership also can foster more limited community engagement and empowerment. We examine some successes and challenges of engaging a regional community using the strengths of paid staff. We conclude that paid staff can offer benefits in terms of connecting local food system efforts by aligning community stakeholder efforts with formalized work efforts of organizations represented by paid staff, which contributes to the compounded impacts of the work. At the same time, relying on paid staff may reinforce existing patterns and power structures.

\section{Keywords}

Community Engagement; Collective Impact; Local Food; Governance 


\section{Introduction and Literature Review}

Proponents of local food systems claim that citizen involvement in food systems contributes to better human health, a cleaner environment, stronger local economies, and more just and equitable communities (Feenstra, 1997; Lyson, 2004). To achieve these outcomes, many local food champions focus on one area, such as economic development or food access, but the literature rarely characterizes organizations that address more than one area (Blay-Palmer et al., 2013). A proceedings report from an evaluator meeting of national health funders ${ }^{1}$ in 2015 concluded that multicomponent, multisector, multisetting, and multilevel interventions have the best record for achieving successful outcomes ("Evaluating obesity prevention efforts," 2015). This suggests that approaches that involve diverse community-based organizations are more likely to be effective than those pursued by a single organization. The more diverse approach may be able to approach issues using multiple strategies from different areas of work and reinforce locally relevant culture from the unique perspective of each organization. We believe this occurs because organizations approaching local food systems development from distinct angles and with differing, yet complementary, goals can effectively create larger systems changes (Blay-Palmer et al., 2013; Wright, Score, \& Conner, 2007). One such multipronged effort is the focus of this paper.

From the beginning, the Northeast Iowa Food and Fitness Initiative (NEIFFI) has drawn upon the frameworks of community capital (Flora \& Flora, 2004), asset-based community development (Kretzmann \& McKnight, 1993), and appreciative inquiry (Cooperrider \& Whitney, 2005) to guide its approach to community development. When Kania and Kramer (2011) put forth the concept of "collective impact," NEIFFI leaders began to adopt the language of collective impact because it aligned with what they were already doing. In this model, cross-sector partners work together toward a

\footnotetext{
${ }^{1}$ Participating health funders included the W.K. Kellogg Foundation, the Robert Woods Johnson Foundation, Nemours, the California Endowment, and Kaiser Permanente. Evaluators from the Centers for Disease Control also were present.
}

common agenda with the support of a backbone organization. The partners engage in mutually reinforcing activities and continuous communication while using a shared measurement system to gauge progress. While community engagement is not explicitly part of the collective impact model, it is consistent with making the approach it frames effective (Raderstrong \& Boyea-Robinson, 2016).

\section{Community Engagement and Program Governance}

A variety of terms can define community efforts to elicit social change, including asset-based community development, participatory action research, local engagement, and public participation. We have chosen to use the term "community engagement" in this article, as the term is commonly used in the broader food and fitness initiative, but we are cognizant of the fact that definitions and perceptions of community engagement differ. Therefore one of our main challenges entering this case study was to determine how NEIFFI leaders define community engagement, compared with how the term is defined in the literature.

One useful and widely accepted approach to codifying the meaning of community engagement is the Public Participation Spectrum developed by the International Association of Public Participation (2014). The spectrum outlines five levels of strategies that leaders and partners can take in a community initiative (see Figure 1). In order from the lowest to the highest level of public impact on decisions, the five levels are Inform, Consult, Involve, Collaborate, and Empower. Each level implies distinct goals for seeking public involvement and sets forth particular types of outcomes for local leaders and partners. The framework takes into account different levels of public participation that may be appropriate depending on the stated goal or goals.

Many philanthropic leaders in the food movement, such as the W. K. Kellogg Foundation, the Robert Woods Johnson Foundation, and PolicyLink, define community engagement as empowerment, meaning that all interested community members have the opportunity to influence actions or make decisions. The emerging literature on local food systems governance emphasizes the impor- 
Figure 1. The Public Participation Spectrum, Followed by an Example of How Each Level Might Occur in Food Systems Work

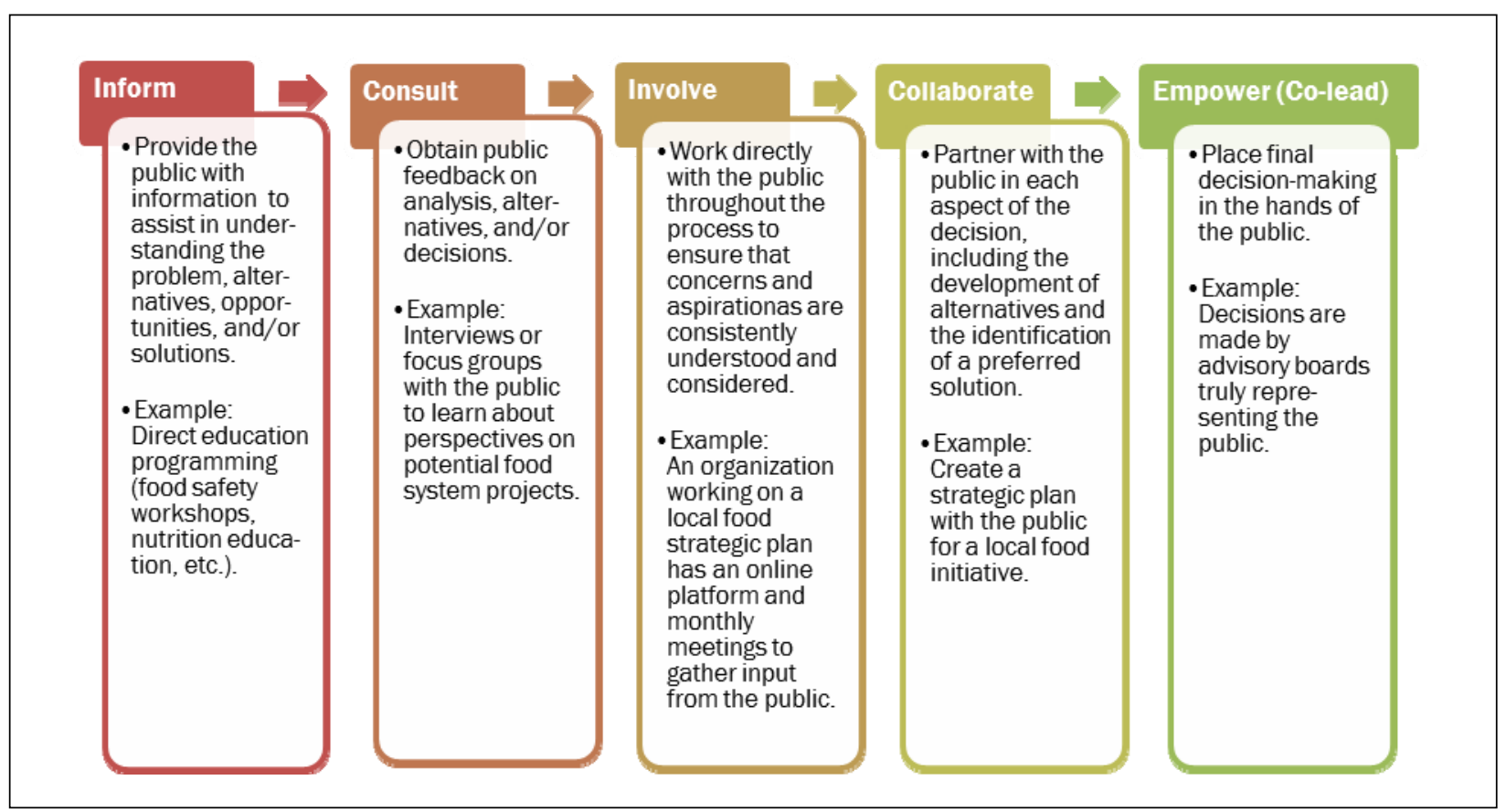

Source: Adapted from the International Association of Public Participation's Public Participation Spectrum (2014).

tance of democratic governance, social justice, and empowerment of local people in alternative agrifood systems (Allen, 2010; Anderson, McDonald, Gardiner, \& McLachlan, 2014). Community engagement literature supports this position, suggesting community engagement efforts that occur higher on the spectrum (Collaborate and Empower) are more desirable (Bagdonis, Hinrichs, \& Schafft, 2009; Hassanein, 2003; Luluquisen \& Pettis, 2014; Perrett \& Jackson, 2015). While the Public Participation Spectrum typology includes several levels of participation, the lower levels of participation such as Inform, Consult, and Involve are less included in community engagement definitions in this literature. ${ }^{2}$

In contrast to food system governance conceptions, collective impact initiatives often are led by professionals working for stakeholder organizations, sometimes referred to as "grasstops" (Raderstrong \& Boyea-Robinson, 2016) rather than the "grassroots" (Himmelman, 2001; Kania,

\footnotetext{
${ }^{2}$ In Cooperative Extension circles, these levels often are described and qualified as Education and Outreach.
}

Hanleybrown, \& Spansky Juster, 2014). This literature provides examples of how reliance on professionals and their organizations in any type of community change initiative can ignore or undermine grassroots leadership. Ultimately, it may prevent an initiative from effectively building on assets available in the community, which suggests that the role of professionals in these efforts is contentious (Kretzmann \& McKnight, 1993, quoted in Barnes \& Schmitz, 2016, p. 36; Wilson, 2006). We have observed that paid professionals often have the time, formal legitimacy, and organizational support to act as primary decision makers, and therefore often take on leadership roles in these efforts. Raderstrong \& BoyeaRobinson (2016) modified the Public Participation Spectrum to include the roles of both grasstops and grassroots engagement by renaming the highest level, "Empower," as "Co-lead," explaining that "Empower" implies that community members (grassroots) are powerless unless the leaders (grasstops) give them power. "Co-lead" implies a place for both grasstops and grassroots leadership in collective impact initiatives. 
Only a few empirical studies are currently covered in the literature on the governance of food value chains and of organizational structures associated with local food systems. This area of study is quite new and theoretical, and has yet to generate much empirical research (Allen, 2010; Clancy, 2014; Erwin, 2016). Empirical studies of local food system governance have focused on municipal land use policy (Beckie, Hanson, \& Schrader, 2013), civic food networks (Anderson et al., 2014), CSAs (Moore, McCarthy, Byrne, \& Ward, 2014), and farmers markets (Gantla \& Lev, 2015). Two authors delve deeply into the challenges of achieving democratic governance in local food systems due to irreconcilable power differences (Anderson et al., 2014; Beckie et al., 2013). Beckie et al. (2013), in their study of the year-long process in Edmonton, Alberta to create a municipal development plan that preserved prime agricultural land, concluded that "inclusivity and dialogue do not guarantee democratic outcomes" (p. 26). In this case, final decision-making power was in the hands of elected officials who put the interests of businesses and developers above those expressed by citizens. Similarly, Anderson et al. (2014) studied a farmer-led civic food network that formed with the expectation that local food systems may offer opportunities for democratic governance valuing consensus, and concluded that civic governance mechanisms, such as cooperation and participation, are just as likely to lead to conflict as consensus.

To this literature, we add a unique perspective on food system governance from our study of a multistakeholder, community-based, local food initiative in a six-county area the size of Connecticut. In grappling with the challenges of achieving democratic governance in local food systems, we introduce a concept of systems leadership that we have observed and fostered over the years as evaluators for the Northeast Iowa Food and Fitness Initiative. We call this concept "shepherding." Although shepherding can mean guiding people in the direction the shepherd chooses, in this context effective shepherds do not choose the agenda, but rather help others in the community to choose what is important and then decide in which direction they want to go. This can be somewhat tricky, since in any locale there often are conflicting views on goals and strategies for achieving these goals. Shepherds, therefore, are not merely neutral participants who support what actors in a local setting want to do. Shepherds also identify and help to manage delicate relational politics, share information, and contribute to articulating conceptual frameworks. They participate in those discussions, public and private, that help to clarify shared definitions of the situation and feasible strategies. Shepherds use their position and power in the community to act in ways consistent with the goals and chosen actions of local participants. Shepherding thus is critical to social justice-based and community-based food systems work, and involves deep listening, network building, strategic guiding, and nudging and/or persuasion to help coalition members step into or expand their work. In this study, we describe the successes and challenges associated with facilitating community action for systems change through employing the resources, power, and skills of paid staff (Emery \& Bregendahl, 2014).

\section{The Northeast Iowa Food and Fitness Initiative}

In 2006, the farmer-based Northeast Iowa Food and Farm (NIFF) Coalition organization formed in five Northeast Iowa counties (Allamakee, Clayton, Fayette, Howard, and Winneshiek). It was the first of several regionally based local food coalitions in Iowa funded by the Leopold Center for Sustainable Agriculture. Twelve such groups today continue to work as part of a statewide network, the Regional Food Systems Working Group (RFSWG), which is active in 78 of Iowa's 99 counties. In 2007, shortly after the creation of the NIFF Coalition, the W. K. Kellogg Foundation (WKKF) launched its Food and Fitness Initiative (FFI), initially implemented at nine locations around the country. The WKKF selected Northeast Iowa for the FFI because of the NIFF Coalition's efforts to support more democratic forms of food system development in an area dominated by industrial agricultural systems. Thus the Northeast Iowa Food and Fitness Initiative (NEIFFI) was born. NEIFFI is in its eighth year of implementation in 2016, but this is the first year without funding from the WKKF Food and 


\section{Figure 2. Northeast lowa Food and Fitness Initiative Theory of Change}

This figure illustrates how participants in NEIFFI understand changes in food and active living systems in response to collaboration and civic engagement.

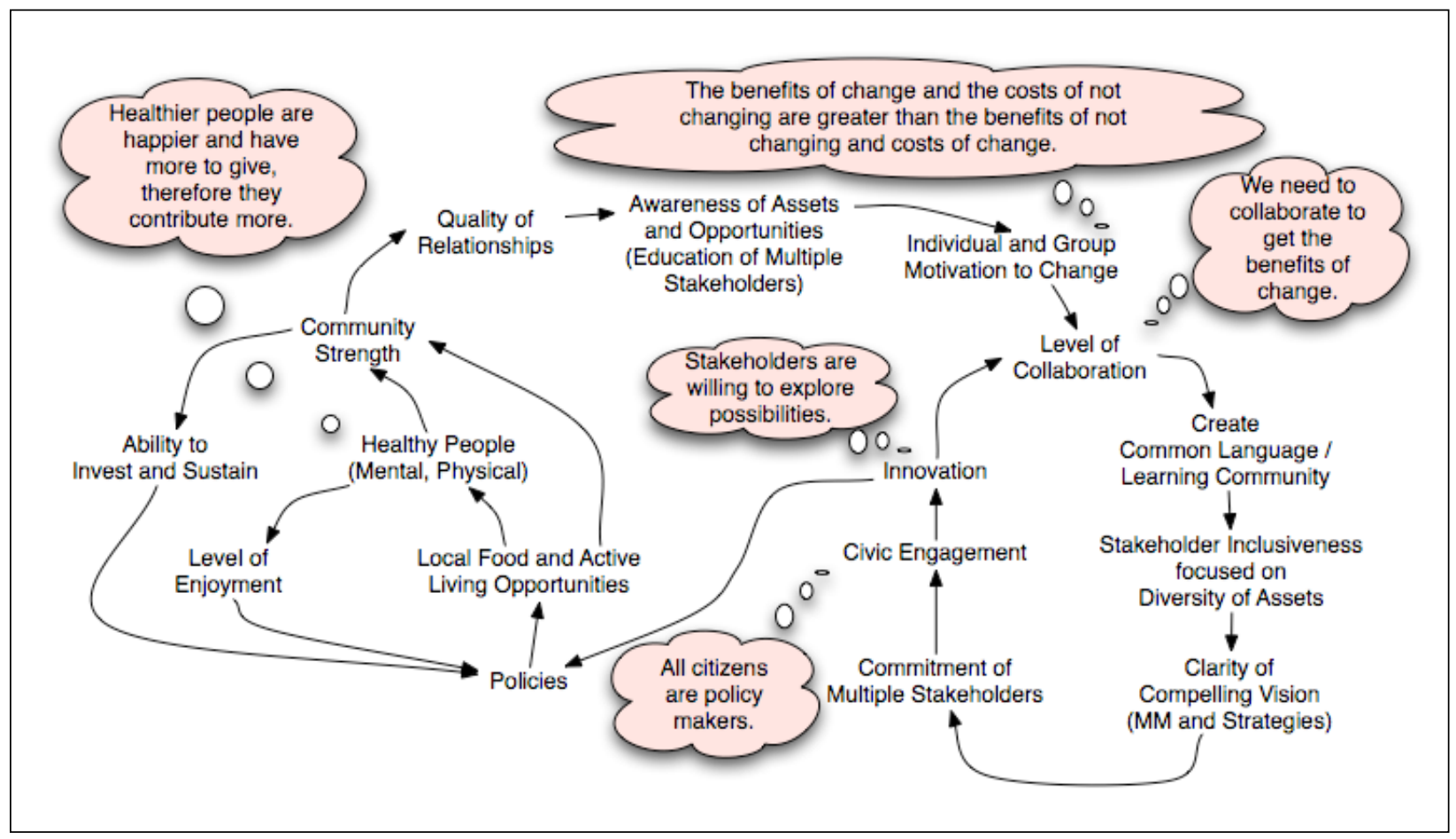

Source: lowa Food and Fitness, n.d., p. 5.

Fitness Initiative. NEIFFI has also secured other sources of funding throughout the years to support its work; together with WKKF funding, investments in NEIFFI over a nine-year period have totaled US\$5 million.

NEIFFI consists of four core partners, each heading one of NEIFFI's strategy areas: Luther College leads school wellness efforts, the Upper Explorerland Regional Planning Commission leads "Safe Routes to School" and active living, Northeast Iowa Community College supports early childhood coordination, and Iowa State University Extension and Outreach (ISUEO) Region 4 leads local food system development. The four core partners have engaged the active participation of more than 700 unique individuals in decisionmaking and implementing local foods and active living activities and programs over the life of the project. $^{3}$

\footnotetext{
${ }^{3}$ This figure does not include those individuals who were reached, but not actively engaged over time.
}

The theory of change underlying NEIFFI's strategy is the proposition that strong and trusting collaborative relationships within a community create the conditions for systems change, leading to healthy, empowered citizens. The conceptual model illustrated in Figure 2 emphasizes community assets as opposed to deficits, commitment to creating a common language and vision, collaboration among multiple stakeholders across different sectors, and civic engagement.

The way in which paid staff have shepherded local food system partners in Northeast Iowa has resulted in stronger support for and use of local foods in a variety of sectors. Paid staff intentionally aligned the goals and work of NEIFFI with the formal work of the host organization(s) or institution(s) they represented in order to (a) reinforce NEIFFI activities with additional financial and administrative support from host institutions, (b) achieve multiple goals with single strokes within the community, (c) compound 
results of the work, and (d) effectively institutionalize community goals within formal organizations. For nearly a decade, we (the authors, in partnership with NEIFFI work group leaders) have tracked significant outcomes of NEIFFI's work through an ongoing evaluation. The evaluation has focused primarily on changes in food systems in Northeast Iowa. Unlike typical program evaluation, therefore, it measures changes in the food system to which NEIFFI has contributed, but which cannot be attributed only to NEIFFI. Below is a list of highlighted outcomes related to NEIFFI food systems work from 2009 to 2016 in Northeast Iowa.

\section{Financial impacts}

- Seventy-six farmers and/or local food enterprises began operations.

- One hundred twenty-two new jobs (44 fulltime) were created in the local food arena, including on- and off-farm jobs.

- The nonprofit Iowa Food Hub (IFH), established in 2013, purchased US $\$ 508,439$ in local foods from farmers or farmer groups in 2015.

- Twenty-four venues implemented programs or infrastructure investments to increase affordability and accessibility of local food, such as farmers market coupon programs for food pantry clients, a new food-box program in a low-income community in Northeast Iowa, and assistance for serving locally raised meats in schools.

\section{School outcomes}

- Comprehensive farm to school programs were started and maintained in 18 school districts that enrolled 11,589 students. These districts had an aggregated free and reduced school lunch rate of $40 \%$.

- Six schools or school districts have achieved the bronze level or higher of the Healthier U.S. Schools Challenge: Healthier Lunchroom Award.

- Seven school districts updated wellness policies to promote local foods and physical activity.

\section{Large-scale local food purchasing}

- Over the 10 years of the project, regional institutional and intermediate market buyers purchased a total of US $\$ 8.5$ million worth of local foods. These purchases have increased steadily since 2005, when ISUEO Region 4 first began tracking the numbers.

- Key partner Luther College locally sourced $35 \%$ of food served on campus in 2013.

- Purchases of local foods by 17 community school districts and one parochial school increased from US $\$ 12,874$ in 2009-10 to US\$63,400 in 2015-16, as shown in Figure 3. The increase in local food purchases from 2013-14 to 2014-15 was due largely to two factors: (1) NEIFFI and four school districts worked together to create a seasonal cycle menu incorporating local foods, and participating schools committed to doubling their purchases of local foods, and (2) buyers were able to order local foods more easily through the newly established Iowa Food Hub.

\section{Methods}

Our analysis was based on grounded theory, an inductive method in which theory emerges from the data, rather than using data to test a preconceived theory (Glaser \& Strauss, 1967). The question we posed as we looked at our first dataset was a simple one: "What do these data say about community engagement?"

We - the evaluators - have kept notes from indepth, reflective phone calls with NEIFFI leaders as well as transcripts of interviews conducted as part of evaluation over the life of the initiative. These notes date back to 2007, with over 150 such documents in our files. We coded these documents to discover themes regarding community engagement using NVivo software, a software package used for analyzing and organizing qualitative data and coding ("What is NVivo?", n.d.). We identified common themes as they relate to notions of community engagement.

The influential role of paid staff in community engagement emerged as a prominent theme during 
Figure 3. Northeast lowa School Purchases of Local Foods Showing the Increase from the 2009-2010 School Year to the 2015-2016 School Year (US\$)

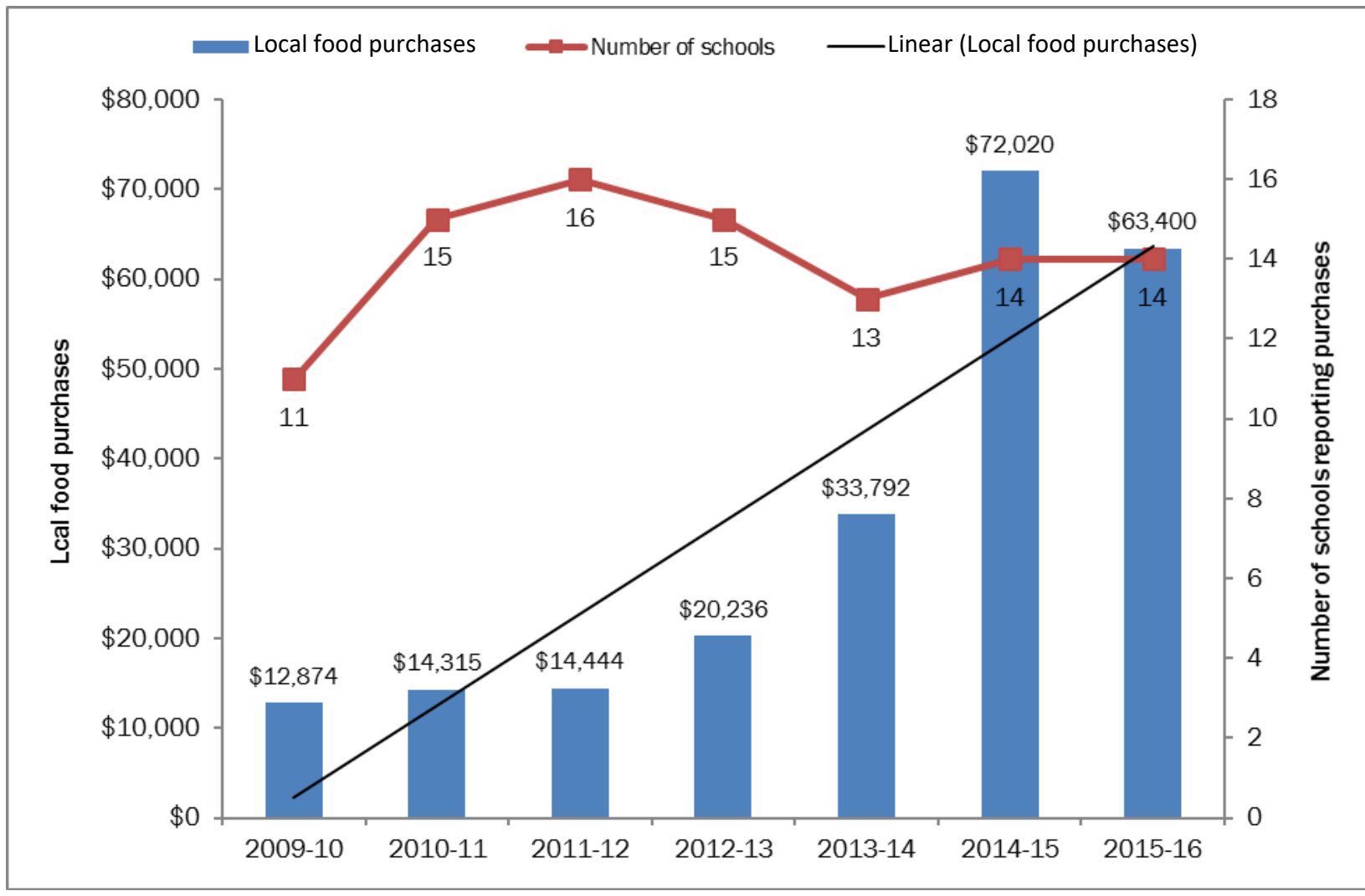

our initial analysis. This motivated us to conduct additional interviews to gain a better understanding of this topic, along with further exploring our original question as to how NEIFFI leaders and participants understand community engagement. The paid staff members at NEIFFI include work group leaders, most of whom are from Northeast Iowa and have worked for NEIFFI for years. The group also covers NEIFFI resource contacts (AmeriCorps and FoodCorps Service members who work in schools to support wellness committees and provide nutrition education and related activities). Salaries for these staff members come from a combination of WKKF and/or other grants and their host institution or employer.

We asked NEIFFI work group leaders to identify partners they believed could share insights on community engagement and the role of paid staff. We selected 19 individuals from the list, and 17 agreed to be interviewed. Interviews were semistructured, using a common interview template, screened initially by NEIFFI work group leaders. These interviews were audio-recorded and transcribed by a third party. We coded the transcripts using NVivo software.

Because we collected data originally for the purpose of evaluation rather than to add to generalizable knowledge, our project did not fit within the federal definition of research. Thus, we were not required to seek Institutional Review Board approval. According to Iowa State University's Institutional Review Board (IRB), "intent to publish or otherwise disseminate study results...does not necessarily mean a project meets the federal definition of research... The important factor is whether a project is designed to develop or contribute to generalizable knowledge" (IRB, 2011, p. 4, emphasis in original). All authors have participated in human subjects training, however, and in this project adhered to human subjects protocols 
by protecting participant confidentiality, informing them of their rights prior to interviews, and obtaining their verbal consent to participate.

\section{Findings and Discussion}

Four themes emerged from the second set of interviews, from topics that several interviewees emphasized or mentioned. Quotations shared below from interviews help summarize or illustrate the themes and represent thoughts shared by a number of interviewees.

\section{Theme 1: Definitions of Community Engagement} NEIFFI interviewees overwhelmingly agreed that community engagement is essential for creating systems change. However, they offered a variety of definitions of community engagement, which were scattered along the Public Participation Spectrum described above. The most common definition, used by slightly more than half the interviewees, was sharing information or resources with community members, thus manifesting their notion of community engagement that falls on the lowest end of the Spectrum ("Inform," Figure 1). Another common definition of community engagement centered on partners sharing a common vision for the community, with six of the 17 defining it in part using this phrase. This second definition reflects a higher level of public impact on decisionmaking. (Although sharing or creating a common vision is not a part of the Public Participation Spectrum, it does speak to the "Collaborate" level, the second-highest Spectrum level.) Only one interviewee described community engagement in terms of empowerment, though the community change model in Figure 2 obliquely refers to empowerment, in the bubbles, stating that "all citizen are policy makers" and "healthier people have more to give."

The diversity of community-engagement definitions demonstrates that NEIFFI is reaching people on a variety of levels depending on their audience. For example, interviewees working in schools and early childhood settings tended to define community engagement as sharing information or resources in the context of informing parents about "new" work. Those interviewees working with school staff who have been more exposed to or experienced with NEIFFI or other organizations were more likely to define it in terms of working toward a shared vision.

In Figure 4, we present a visualization of the elements that interviewees described when defining community engagement, with supplementation for context and comparison based on observational data collected from the broader statewide local food system network (the Iowa Regional Food Systems Working Group). Most of the 12 local food groups in Iowa reported using two common strategies to develop local food systems in their area: (1) direct programming (Inform, Consult, and Involve, according to the Public Participation Spectrum), and (2) coalition building (the Collaborate level of the Spectrum). The difference between direct programming and coalition building lies in

\section{Figure 4. Evolution of Community Engagement for Systems Change}

Shepherding helps direct programming and coalition building toward systems change.

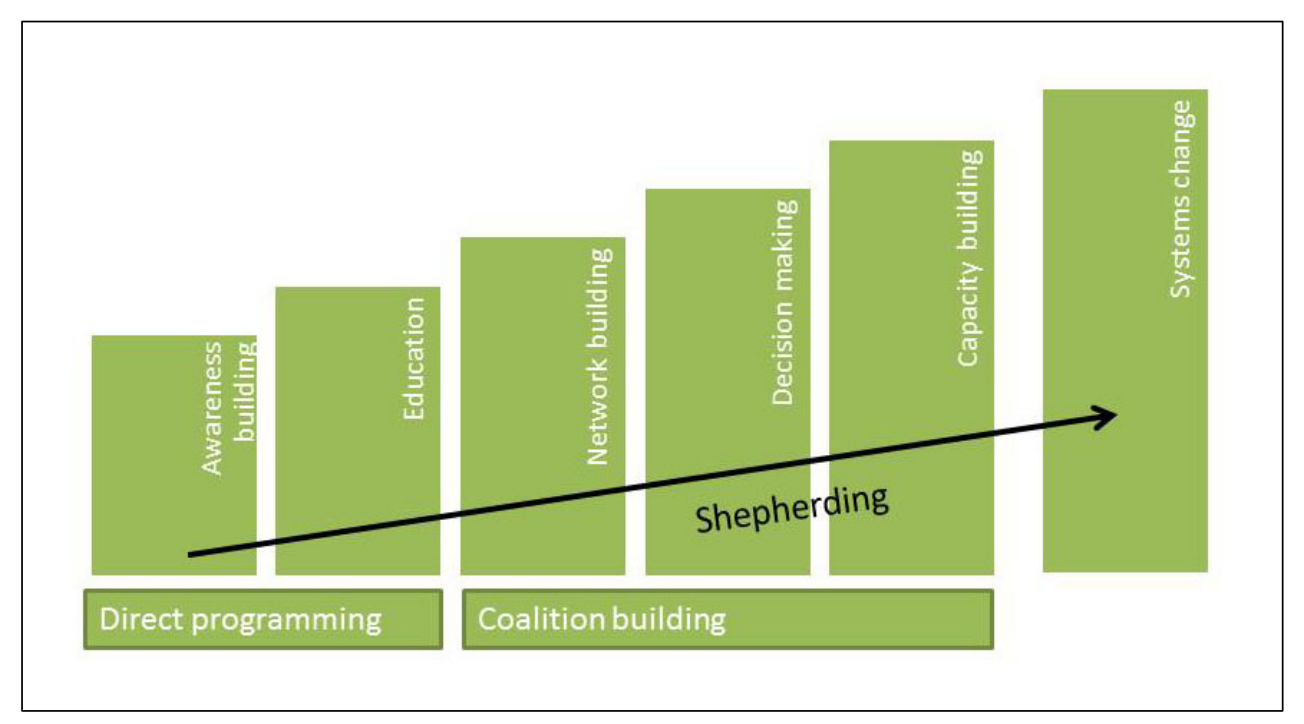


the direction of information sharing as well as the type of information shared. Direct programming relies on disseminating publicly available information, whereas coalition building relies on sharing implicit and tacit up-to-date information. The latter involves information, often exchanged informally among peers and trusted partners who have never recorded their wisdom, making it unavailable from any other source (Pirog, R., personal communication, 2010). Effective coalition building also includes strategic-planning meetings and joint problem solving, rather than merely reporting results (Kania \& Kramer, 2011).

Shepherding, in Figure 4, ties together all the community-engagement tactics by helping those initially engaged in direct programming to find their role in the coalition and then to implement changes in their sphere of influence.

To illustrate, we share the example of how NEIFFI worked with local food service directors to develop a seasonal cycle menu. In the early phases of the initiative, NEIFFI regularly hosted workshops for food service directors (FSDs) and staff to build the skills needed to incorporate local foods into school menus (an example of Education in Figure 4). One such training occurred during spring 2012, a few months before the Healthy Hunger-Free Kids Act instituted new school food standards. Following the training, several FSDs were conversing about the challenges they faced in revamping their menus to meet the new regulations. One suggested they work together to create new menus. NEIFFI staff overheard the conversation, which prompted the idea of creating a common menu incorporating local foods. Following the conversation, NEIFFI staff applied for and received funding from the Leopold Center for Sustainable Agriculture to create a seasonal, cycle menu, with six FSDs committing to collaborate (the number later decreased to four). Through a connection between NEIFFI staff and a local food initiative in a neighboring region, the FSDs and NEIFFI staff hired a former FSD with extensive consulting experience with incorporating local food into menus. The consultant and two NEIFFI staff members met monthly with participating FSDs to create a five-week menu that met the new federal regulations and could use locally grown foods.
Participating FSDs contributed their favorite recipes and tested new ones, brought their feedback to the monthly meetings, and worked with the consultant to adjust the recipes and menus (examples of Decision Making in Figure 4). The consultant also visited the four school district kitchens on a regular basis to receive feedback on the menu from the entire food service staff. Initially, NEIFFI staff wanted to begin incorporating local foods into the menu immediately, but FSDs were reluctant to do so, wanting to create a workable menu prior to adding local food to the mix. Therefore, for the first year the group focused exclusively on creating a menu that pleased FSDs, kitchen staff, and kids. The FSD group then began adding local foods in the 2013-14 school year, doubling local food purchases in that year and again in the 2014-15 school year (showing how development of the seasonal cycle menu led to Systems Change, the highest stage in Figure 4).

An explicit focus on empowerment is largely absent from Figure 4. While other Food and Fitness sites nationally_all operating in urban areas - have embraced the idea of empowerment to lead their community engagement work, many of them are led by experienced social justice organizations with strong connections to existing grassroots organizations (Luluquisen \& Pettis, 2014; Sands, Bankert, Rataj, Maitin, \& Sostre, 2014). We note that such organizations are generally lacking in rural Northeast Iowa, as the grassroots are not as well organized and selfidentified, and thus less able to take action. Nevertheless, NEIFFI has demonstrated success in organizing and empowering two grassroots audiences: local food farmers (organized through the NIFF Coalition) and youth (organized through FFI Youth 4-H Clubs in schools). For example, one young person explained how participating in FEEST (an FFI/4-H youth program focused on food and empowerment) provided him with skills and practice to speak up when he wants something changed at his school or in his community. As a result, he and a few friends planned to ask the school board to repeal a policy that required freshman students to take a study hall: "We're going to go up and talk to the school board and see 
if we can do something. Before I would have said, 'I hope someone else will do it and I won't have to worry about embarrassing myself."'

Other than these two audiences, NEIFFI has been more successful in engaging and empowering partner organizations within the region, such as preschools, Head Start organizations, schools, and nonprofits, which supports the idea that collective impact initiatives may be more successful if co-led by the grasstops and the grassroots, sharing power rather than only empowering the grassroots (Raderstrong \& Boyea-Robinson, 2016).

\section{Theme 2: Balancing Programming with Coalition Building}

Although it seems low on the list of community engagement priorities, interviewees explained that outreach through direct programming is essential as an entry point for inviting people to engage in work and creating an inclusive environment. However, direct programming alone is insufficient for keeping them engaged or redistributing power. As one interviewee explained:

There's always... going to be that community awareness team and you're always going to be out there with at least the baseline message of: This is Food and Fitness; this is what we do and this is what we're trying to achieve. But, how do you balance that with...looking at the strategic groups where you can start to apply pressure to...change.

Local food system "shepherds" can help to guide collective, coordinated action that leads to systems change. Direct education and coalitionbuilding strategies without shepherding can lead to passivity and ineffectiveness. Based on our observations of how leaders in the NEIFFI have combined direct programming and coalition building toward systems change, we added shepherding to Figure 4 as the essential factor that ties everything together and leads to systems change. Through our work as evaluators of the RFSWG, we have observed that some local food leaders simply bring together large groups of people, hoping that this will automatically lead to coordinated action. Sometimes coordinated action does happen, but generally shepherding is necessary to achieve systems change. One interviewee recognized the shortcomings of direct programming and networking in eliciting systems change, and the importance of shepherding:

[Regarding] some of the groups [in our local network] — how can we actually push them further [in their own work in collaboration with us] instead of just creating awareness and hoping that they'll jump on the bandwagon with us?

\section{Theme 3: Engaging Ready Partners}

Interviewees described themselves as engaging more strongly with specific partners as the initiative has evolved through different cycles of local food work. NEIFFI interviewees cited numerous examples:

- Schools. NEIFFI has collaborated with 18 school districts in many different ways. ${ }^{4}$ In 2014, initiative leaders made the decision to place NEIFFI "Resource Contacts" or RCs only in schools that chose to contribute to the Resource Contact's stipend. Since then, 10 schools on average have contributed funds to have an RC each school year.

- Farmers. After NEIFFI formed, the NIFF Coalition continued to learn through bringing various actors together, with monthly meetings that connected farmers and farm service providers, and brought in speakers to talk about topics such as food aggregation and food safety. NIFF Coalition attendance eventually started to drop, however, for reasons unknown to us. The group that remained chose to discontinue regular meetings. At about the same time, in 2011, ISU Extension and Outreach

\footnotetext{
${ }^{4}$ Schools have been engaged through encouraging school administrators to attend special FFI meetings designed for them, creating youth teams, educating school food service staff on preparing vegetables and meals from scratch, working with school wellness teams, funding schools in order to increase healthy food access and physical activity, providing nutrition and local foods education to PreK-12 students, supporting farm to school activities, helping to fund, establish, and maintain school gardens, etc.
} 
Region 4 secured funds to hire a value-chain coordinator to address creating a system to aggregate and distribute food from small and midsize farms in Northeast Iowa to larger buyers. The coordinator began work by holding strategic planning meetings with farmers and food buyers, which he deemed unsuccessful because no one committed to action. As a result, the coordinator worked with a small group of farmers and grocers, rather than the entire NIFF Coalition, to pilot various strategies for food aggregation and distribution. These pilot programs eventually led to the creation of the Iowa Food Hub (IFH).

To create system change, NEIFFI leaders eventually concluded that engaging partners who demonstrate readiness to implement change yields more, and more rapid, progress than engaging a broad base of partners with varying degrees of interest, time, and resources. This has meant leaving some partners behind, at least for a time. One interviewee struggled with deciding how to invest in "ready" partners:

You've got these people who are siphoning time and energy who aren't going to go any further. You almost have to just let them go so that you can focus time and energy on going deeper with those who are ready. And that's a hard decision because...we want to help everybody... We know the system has to change but, at the same time, [shouldn't] you nurture those innovators so that they can be the leaders for system change?

NEIFFI also has had partners who engage for a time and then disconnect once they have achieved their goal. For example, one of the FSDs who met monthly with a technical-assistance provider to create a new school menu described those meetings fondly, but expressed relief they had ended:

It was nice to have the other food service directors in one place. That's where I learned everything...I miss that because we don't get together any more...We do see each other, but not monthly like we used to. That was kind of nice, you know?...It's good and it's bad that we don't meet. I miss the communication, but everybody is busy and everybody has their own extra stuff that they do.

Shepherds can keep such people in mind, and invite them to reengage when new opportunities arise.

\section{Theme 4: The Role of Paid Staff in Community Engagement}

Paid NEIFFI staff have played an essential role in building the local food system in Northeast Iowa. Interviewees were in general agreement that NEIFFI could not have achieved as much if it had relied on volunteers alone. One staff member of an early childhood partner group described how the Farm to Preschool program would never have taken off in Head Start and other early child-care settings without the paid leadership and time investment of NEIFFI's early childhood coordinator.

Similarly, another interviewee explained how the IFH would not have started without the work of the value chain coordinator and other Extension staff:

I think it was [Extension's] skill set and their talents and their understanding of what the potential was and their vision of what they had identified that allowed [the development of the Iowa Food Hub]. I think their dedication and their passion for what the potential outcomes [created a resilient team]. [The value chain coordinator] would drive anywhere in his own personal car and load up boxes...For somebody who didn't even own that business, he went above and beyond.

Despite agreement that paid staff are critical to NEIFFI, the initiative has struggled with defining appropriate roles for them. An example of the difficulty is the NEIFFI role in the IFH and the NEIFFI Regional Leadership Council. 
NEIFFI leaders formed the Iowa Food Hub board, with seven members consisting of smallscale farmers and community members, and the separate Regional Leadership Council, a 23member council that meets quarterly to guide NEIFFI. These two groups were intended to ensure that community members had opportunities to influence the direction of IFH and NEIFFI. The governance structures of these two organizations were modeled on those of existing rural organizations - such as farmer cooperatives, gas cooperatives, and telephone cooperatives - which are commonly governed by boards. FFI leaders sought for these boards a combination of people already involved with the IFH or NEIFFI and voices who were not currently represented. They did so in hopes that being part of a formal decision-making body would increase the breadth of engagement and diversify leadership. However, neither group has participated significantly in local food system decision-making, despite efforts by paid NEIFFI staff to build their capacity to do so. NEIFFI staff intended to reduce their own leadership role by creating the IFH Board and the Regional Leadership Council, but transferring leadership has not been an easy process. Community members have limited time to dedicate to NEIFFI work, which is another challenge. One NEIFFI staff member described the situation, using working with the IFH Board as an example of the problem:

It was this dance between Extension playing a leading role and trying to [build community] capacity [to lead], but you're trying to transfer the ownership and the capacity to a group of community members that are already stretched thin, going to too many meetings, and...not looking for one more. But... they need a piece of skin in the game. This no longer can be our show; it can't be Extension's show. But that transfer of ownership with capacity into the community is not a short journey.

Interviewees indicated that high levels of trust in NEIFFI staff by community members were limiting the motivation of community members to take a lead in making decisions. Many community members trust paid staff to make decisions, rather than feeling a need to articulate their own views. Furthermore, they may not have the time to be involved in further decision making, or do not have the time or energy to volunteer. A farmer on the IFH Board described the situation:

Things have grown so fast that it is hard to keep up, to be somebody who really does influence the direction. But, I also think that that's not really the role of a board member. It isn't really to direct the organization. That's the employees. That's the people that you put in charge and then as a board you meet to have that interchange and to offer ideas and opinions.

Others stated that they felt work group leaders, who are paid NEIFFI staff, were better qualified to make decisions, as expressed by one member of the Regional Leadership Council:

I essentially went to the [Regional Leadership Council] meetings to hear about what was going on. We got to look at their reports and their grants and budget and everything but I wasn't deciding...I felt like the [work group leaders] did that. I mean, they knew way more about it than we did.

Finally, Extension's role in founding IFH has been contentious. Iowa State University Extension and Outreach started IFH with the goal of increasing access to healthy local foods among low-income families, but has received sharp criticism regarding the part it has played. Some critics believe that Extension, as a publicly funded institution, should not provide a competitive economic advantage to participating farmers over nonparticipating farmers and private local-food distribution businesses. Extension staff responded to these criticisms by clarifying Extension's role with IFH. Extension primarily partners with IFH in order to offer technical assistance, conduct research, and pilot programs from which others can learn, and 
administer grants for research and food access programs, which the food hub could not do without support from Extension. Despite this clarification, Region 4 Extension continues to receive criticism from within and outside the region, as some believe that IFH is distorting the market by paying some of its operational costs with grants-most of which have been publicly funded - giving it an advantage over for-profit companies. At the same time, IFH is addressing a lack of access to healthy food by delivering healthful local foods to schools and subsidizing food deliveries in low-income communities with profits from sales to more affluent customers. Thus, Extension is assisting an organization that is addressing a market failure. In addition, there is a push for Extension, both in Iowa and nationally, to step out of its traditional role of direct programming into new frontiers of coalition building and systems change (Dunning et al., 2012; Raison, 2010). Resistance to efforts by a public institution to address inequity in the food system by reducing barriers to healthy food access illustrates one of the continuing challenges the Northeast Iowa group faces. More effective shepherding is warranted in this situation to foster trust and perhaps support among critics.

\section{Conclusions and Recommendations}

The experience of the Northeast Iowa Food and Fitness Initiative has yielded important lessons on changing food systems through community-based approaches. First, community engagement can happen at a variety of levels, ranging from informing people in general to including a wide range of people in collaborative decision-making and implementation. That said, given the needs of many communities, even the lowest levels of community engagement (which include informing and educating) could easily and quickly consume all the limited resources of a coalition. Thus the process of making aligned policy, systems, and environmental changes that are consistent with the goals of the broader food system effort can likely be improved by identifying organizations and partners who can implement change and invest their own time and resources.

Second, we learned that having paid staff filling the role of shepherd offers great benefits in terms of connecting local food system efforts with similar efforts of existing organizations and institutions within the community, contributing to compounded impacts of the work. However, strongly connecting grassroots efforts with grasstops organizations may reinforce existing patterns and power structures, especially in places like Northeast Iowa, where the grassroots base is neither organized nor energized.

The work of identifying and engaging "ready" partners raises the specter of "unready" partners and power dynamics. So-called "unready" partners may include people and organizations who do not have the interest, time, or resources to get involved. They also may include members of marginalized, resource-poor groups, those traditionally excluded from decision-making processes. Indeed, this has been a perennial challenge for NEIFFI. It was recognized early in the planning stages when NEIFFI leaders tried unsuccessfully to engage Northeast Iowa's few ethnic minority communities ${ }^{5}$ (Erbstein, 2013), who have a history of financial, cultural, social, and political disenfranchisement and distrust in formal institutions. Viewed from another perspective, it may be that NEIFFI leaders were not "ready" to engage uninvolved populations, because these leaders lacked the long-term capacity, social capital, cultural acuity, and/or sociopolitical resources to engage marginalized populations and catalyze power redistribution. The difficulty of changing power structures in Northeast Iowa, where the adult population is relatively racially homogeneous ( $97 \%$ white), speaks to the difficulty of improving equity in places where the populations are significantly more racially heterogeneous.

Finally, perceptions by other farmers from

\footnotetext{
${ }^{5}$ A case in point is the community of Postville, the site of an Immigration and Customs Enforcement Agency raid of a kosher slaughterhouse and packing plant in 2008. ICE agents arrested nearly 400 immigrant workers of South and Central American indigenous descent. Several plant employees and managers were indicted on charges of child labor violations, harboring undocumented workers, and aggravated identity theft. Although the owners were never charged, the plant's chief executive was convicted of bank fraud and sentenced to 27 years in prison.
} 
different parts of the state that the use of public funds "distorts" free market competition ultimately interferes with the ability of the initiative to make more progress on increasing healthful food access for low-income families. Rural areas without a strong base of independent and influential philanthropic funding, combined with a dearth of strong grassroots social justice groups, may be facing a similar situation. Furthermore, if the private sector fails to address healthful food access while simultaneously working to prevent the public sector from doing so, who will take on this important work in rural America?

We anticipate this case study to be valuable to other local food system initiatives seeking to engage the community while building on the strengths of paid staff. This case study offers evidence that often the best use of staff time can be working with partners who already have the capacity and willingness to implement change. Yet this creates a dilemma as to whether and/or how to engage with partners who are not "ready," because they lack the motivation, capacity, or resources to make changes. The concept of shepherding as a best practice can help address and potentially change these conditions and bring partners deeper into the work and the community. Further research into how initiatives can maintain a balance between engaging ready partners (those with motivation, resources, and the capacity to act) and unready partners (those who are unmotivated, under-resourced and/or lacking the capacity to act via organized, conventional ways) would be insightful. This study also shows that high trusting relationships that exist between paid staff and community members can have a downside: It may cause community members with low motivation to become engaged less actively in decision-making, which other initiatives may want to keep in mind. Further research would be useful to help understand how to counter reluctance to engage as a result of high trust environments.

\section{References}

Allen, P. (2010). Realizing justice in local food systems. Cambridge Journal of Regions, Economy and Society, 3(2), 295-308. http://dx.doi.org/10.1093/cjres/rsq015
Anderson, C., McDonald, W., Gardiner, J.-L., \& McLachlan, S. (2014). Navigating the fault lines in civic food networks. Journal of Agriculture, Food Systems, and Community Development, 4(3), 79-99. http://dx.doi.org/10.5304/jafscd.2014.043.009

Bagdonis, J., Hinrichs, C., \& Schafft, K. (2009). The emergence and framing of farm-to-school initiatives: Civic engagement, health and local agriculture. Agriculture and Human Values, 26(1), 107-119. http://dx.doi.org/10.1007/s10460-008$\underline{9173-6}$

Barnes, M., \& Schmitz, P. (2016). Community engagement matters (Now more than ever). Stanford Social Innovation Review, 14(2), 32-39. https://ssir.org/

Beckie, M., Hanson, L., \& Schrader, D. (2013). Farms or freeways? Citizen engagement and municipal governance in Edmonton's food and agriculture strategy development. Journal of Agriculture, Food Systems, and Community Development, 4(1), 1-17. http://dx.doi.org/10.5304/jafscd.2013.041.004

Blay-Palmer, A., Knezevic, I., Andrée, P., Ballamingie, P., Landman, K., Mount, P., ... \& Skinner, K. (2013). Future food system research priorities: A sustainable food systems perspective from Ontario, Canada. Journal of Agriculture, Food Systems, and Community Development, 3(4), 227-234. http://doi.org/10.5304/jafscd.2013.034.029

Clancy, K. (2014). Food system governance. Journal of Agriculture, Food Systems, and Community Development, 4(2), 1-4. http://dx.doi.org/10.5304/jafscd.2014.042.012

Cooperrider, D. L, \& Whitney, D. (2005). Appreciative inquiry: A positive revolution in change. San Francisco: BK.

Dunning, R., Creamer, N., Lelekacs, J. M., O'Sullivan, J., Thraves, T., \& Wymore, T. (2012). Educator and institutional entrepreneur: Cooperative Extension and the building of localized food systems. Journal of Agriculture, Food Systems, and Community Development, 3(1), 99-112. http://dx.doi.org/10.5304/jafscd.2012.031.010

Emery, M. E., \& Bregendahl, C. (2014). Relationship building: The art, craft, and context for mobilizing the social capital necessary for systems change. Community Development, 45(3), 279-292. http://doi.org/10.1080/15575330.2014.903986 
Erbstein, N. (2013). Engaging underrepresented youth populations in community youth development: Tapping social capital as a critical resource. New Directions for Youth Development, 138, 109-124. http://dx.doi.org/10.1002/yd.20061

Erwin, A. (2016). Pondering farmworker justice: The visible and invisible borders of social change. Journal of Agriculture, Food Systems, and Community Development, 6(2), 1-5. http://dx.doi.org/10.5304/jafscd.2016.062.007

Evaluating obesity prevention efforts: What have we learned? Highlights from a conversation of funders and evaluators. (2015). Meeting Proceedings. Oakland, California: California Endowment, Kaiser Permanente, Robert Wood Johnson Foundation, R. W. Kellogg Foundation. http://hsrc.himmelfarb. gwu.edu/sphhs centers redstone/

Feenstra, G. W. (1997). Local food systems and sustainable communities. American Journal of Alternative Agriculture, 12(1), 28-36. http://dx.doi.org/10.1017/S0889189300007165

Flora, C. B., \& Flora, J. L. (2004). Rural communities: Legacy and change. $2^{\text {nd }}$ ed. Boulder, Colorado: Westview.

Gantla, S., \& Lev, L. (2015). Farmers' market or farmers market? Examining how market ownership influences conduct and performance. Journal of Agriculture, Food Systems, and Community Development, 6(1), 49-63. http://dx.doi.org/10.5304/jafscd.2015.061.005

Glaser, B. G., \& Strauss, A. L. (1967). The discovery of grounded theory: Strategies for qualitative research. Piscataway, New Jersey: Aldine Transaction.

Hassanein, N. (2003). Practicing food politics: A pragmatic politics of transformation. Journal of Rural Studies, 19(1), 77-86. http://dx.doi.org/10.1016/S0743-0167(02)00041-4

Himmelman, A. T. (2001). On coalitions and the transformation of power relations: Collaborative betterment and collaborative empowerment. American Journal of Community Psychology, 29(2), 277284. http://dx.doi.org/10.1023/A:1010334831330

Institutional Review Board [IRB]. (2011). Do I need to submit an IRB application? Ames, Iowa: Iowa State University, IRB. http://www.compliance.iastate. edu/irb/forms/docs/rih-self-test.docx International Association for Public Participation.
(2014). The IAP2 public participation spectrum. Louisville, Colorado: Author. Retrieved from https://www.iap2.org/resource/resmgr/Foundatio ns Course/IAP2 P2 Spectrum.pdf?hhSearchTerm $\mathrm{s}=\% 22$ spectrum $\% 22$

Iowa Food and Fitness. (n.d.). Northeast Iowa Food and Fitness Community Action Plan 2012-2016. Retrieved from http://www.iowafoodandfitness.org/ uploads/PDF File 37722925.pdf

Kania, J., Hanleybrown, F., \& Spansky Juster, J. (2014). Essential mindset shifts for collective impact. Stanford Social Innovation Review, 12(4), 2-5. https://ssir.org/

Kania, J., \& Kramer, M. (2011). Collective impact. Stanford Social Innovation Review, 9(1), 36-41. https://ssir.org/

Kretzmann, J. P., \& McKnight, J. L. (1993). Building communities from the inside out: A path toward finding and mobilizing a community's assets. Evanston, Illinois: Center for Urban Affairs and Policy Research, Northwestern University.

Luluquisen, M., \& Pettis, L. (2014). Community engagement for policy and systems change. Community Development, 45(3), 252-262. http://dx.doi.org/10.1080/15575330.2014.905613

Lyson, T. A. (2004). Civic agriculture: Reconnecting farm, food, and community. Lebanon, New Hampshire: Tufts University Press/University Press of New England.

Moore, O., McCarthy, O., Byrne, N., \& Ward, M. (2014). Reflexive resilience and community supported agriculture: The case that emerged from a place. Journal of Agriculture, Food Systems, and Community Development, 4(3), 1-17. http://dx.doi.org/10.5304/jafscd.2014.043.007

Perrett, A., \& Jackson, C. (2015). Local food, food democracy, and food hubs. Journal of Agriculture, Food Systems, and Community Development, 6(1), 1-6. http://dx.doi.org/10.5304/jafscd.2015.061.003

Raderstrong, J., \& Boyea-Robinson, T. (2016). The why and how of working with communities through collective impact. Community Development, 47(2), 1-13. http://dx.doi.org/10.1080/15575 $\underline{330.2015 .1130072}$

Raison, B. (2010). Educators or facilitators? Clarifying extension's role in the emerging local food systems movement. Journal of Extension, 48(3), 1-5. https://joe.org/joe/2010june/comm1.php 
Sands, C. H., Bankert, S. C., Rataj, S., Maitin, M., \& Sostre, J. (2014). "Call for Partnerships": An innovative strategy to establish grassroots partnerships to transform the food and fitness environments. Community Development, 45(3), 263-278. http://dx.doi.org/10.1080/15575330.2014.902856

What is NVivo? (n.d.). Doncaster, Victoria, Australia \& Burlington, Massachusetts: QSR International. http://www.qsrinternational.com/what-is-nvivo
Wilson, G. (2006). Beyond the technocrat? The professional expert in development practice. Development and Change, 37(3), 501-523. http://dx.doi.org/10.1111/i.0012-155X.2006. 00488.x

Wright, W., Score, M., \& Conner, D. S. (2007). Food system makers: Motivational frames for catalyzing agri-food development through multi-stakeholder collaboration. Community Development, 38(3), 39-59. http://dx.doi.org/10.1080/15575330709489828 